\title{
MEASURING COMMUNITY DEVELOPMENT: PERSPECTIVES FROM LOCAL GOVERNMENT IN WESTERN AUSTRALIA
}

\section{Sherry Saggers ${ }^{1}$, May Carter ${ }^{1}$, Stuart Boyd ${ }^{2}$, Trudi Cooper ${ }^{1}$ and Christopher Sonn ${ }^{1}$}

Local government in Australia has become an important site for discussions about community development and community well being, as increasing numbers of community services are being devolved to this level. Pressures towards greater accountability and demonstration of competitiveness, stemming from the implementation of National Competition Policy have led to attempts to better measure community development activities. In this paper we report on research conducted among management, elected members and community workers at five Western Australian Local Government Authorities which explored the nature and appropriateness of community development measurement. We found workers at all levels of employment struggling, not simply with notions of measurement, but also with fundamental understandings of community development.

\section{Introduction}

Across Australia over the past few years policy makers, managers, and community workers have been talking about developing measures which indicate community well being (Salvaris 2000). There are diverse antecedents for this focus. The most immediate context to this is the burgeoning international literature on the importance of social capital, rather than simply relying on economic indicators of growth (Bourdieu 1985; Putnam 1993; Cox 1995; Cobb \& Rixford 1998). This literature explores how social relationships and networks provide one important dimension to people's understanding of what constitutes the good life. Long before social capital dominated academic and popular discourses around well being, however, community development approaches have focused on issues pertaining to citizen empowerment, participation and social justice and the way in which these factors are inextricably

\footnotetext{
${ }^{1}$ Institute for the Service Professions, Edith Cowan University

${ }^{2}$ Adelaide City Council
} 
linked to economic development and the wealth of nations. Much of this debate has occurred at an academic level, but others have attempted to translate these idealistic notions about the nature of community to the level of practice, such as the impact of social capital on health (Kawachi et al 1997; Leeder \& Dominello 1999). Local governments, too, have been the sites of some of this work, predominantly in the eastern states (Hornby 2000; City of Melbourne 2001).

Parallel to these developments have been pressures towards greater accountability at local government level stemming from the implementation of National Competition Policy in Australia. This has led to attempts to demonstrate competitiveness by benchmarking council activities across Australia, and to develop performance measurement for core business activities. For many councils the measurement of performance has been an attempt to demonstrate competitiveness and for others it is a means to continuously improve quality of services and therefore improve community well being. This paper provides a brief history of this development and presents the results of research in Western Australia which explored the impact of these performance measurement trends on a number of local government authorities.

Predominantly we sought to understand how the pressures from these trends affect community workers within local government. We conclude that workers at all levels of local government are struggling, not simply with the measurement of community development, but also with fundamental definitions of the nature of community development itself.

\section{Background}

\section{National Competition Policy and local government in Australia}

In Australia, more than two decades of 'reform' designed to produce a more internationally competitive economy have seen the imposition of private sector management models on the public sector. As part of this, National Competition Policy (NCP) was introduced in 1995 with the aim of reviewing and reforming all laws that restrict competition, and ensuring that any new restrictions provided a net community benefit. Improvements in performance, brought about by structural reform, would ensure that government businesses did not enjoy unfair advantages or disadvantages when competing with private businesses (National Competition Council 1999:4). 
Numerous concerns have now been raised that the implementation of competition policy is contributing to cutbacks in government services as local government, in particular, is increasingly subject to market forces and contractualism. For example, local government childcare and recreation services that compete with private sector providers, are required to evaluate their performance and address issues of competitive advantage in the marketplace (Industry Commission 1997:4-5). In many cases this meant that recurrent funding was replaced by a tendering process, requiring local community based agencies to compete with larger welfare agencies and commercial organisations to provide specified community services.

Salvaris (2000) notes that local communities have been hardest hit with reductions in local government community services and infrastructure. Citizens have been transformed into customers, with decreased access to services. While measurement of economic performance was readily accomplished, the implementation of tendering has raised a number of issues about how 'quality' and 'value for money' ought to be measured (Victoria University of Technology 1997).

In part as a reaction against trends to define and measure progress purely in economic terms, a wide range of community and social indicators have been developed in an attempt to measure the well-being of citizens (Cobb \& Rixford 1998; Salvaris 2000). But what is the relationship between these often-global measures of social/ community well being and attempts to measure local government achievements in community development and community services? Like the more global community indicators, have these sometimes been hijacked by largely economic indicators as a management tool to demonstrate accountability and competitiveness (Salvaris 2000)?

\section{Benchmarking and performance measurement}

Benchmarking claims to offer an effective performance measurement tool that was readily accepted by Australian industry (Macneil, Testi, Cupples \& Rimmer 1994). The benchmarking process relies on creating standardised measures of performance and its adoption within local government provided a method of cross-council comparison and measurement of continuous improvement within councils.

In 1995, a major project was undertaken by the Victorian Office of Local Government to establish benchmarking procedures for local government (Commonwealth Department of Housing and Regional Development 1995). Performance indicators suggested were customer satisfaction, quality, cost and time (timeliness, responsiveness) of council services. 
In 1998 a South Australian survey of 33 councils on local government performance and benchmarking (Collins \& Waite 1998) found that benchmarking was not widespread, with only eight councils (24\%) having undertaken benchmarking in any form. Of this group, only 15 per cent had linked their performance measurement system to their strategic or corporate plan and less than 10 per cent were measuring performance in the community services area. Reasons given for not participating in benchmarking or performance measurement included a lack of resources, and both staff and technical knowledge to carry out such measurement.

In 1999 the national Local Government Community Services Association of Australia (LGCSAA) explored the use of benchmarking as a method of measuring and comparing performance between local government authorities in community service provision and community development. There was recognition by the LGCSAA of the historical resistance to measurement in the area of community services/development, but an acceptance that benchmarking could and should be seen as a continuous improvement tool. What was required, it was argued was:

Measures that are valid, rewarding, integral with everyday activities, useful, sensible and locally relevant. They must also enable us as workers and decision-makers to develop a holistic view of the service or activity within a social policy context, and to inform changes in practice and policy, both on a local scale... and more generally (LGCSAA 1999:1).

According to the LGCSA benchmarking needed to be undertaken in an environment in which partnerships, not competition, were paramount. This raises the question as to the purpose of benchmarking — to improve community well being or to demonstrate competitiveness.

In spite of this growing literature on measurement in local government throughout Australia, many in local authorities appear to regard these trends with considerable caution. In Western Australia, a report on the use of key performance indicators in local government noted that, although many performance measures had been developed, many councils were unaware of the statutory requirements for performance measurement, and the necessity of linking those measures to strategic objectives. When asked to identify categories of council activities that could beneficially be measured, all community services (excluding the provision of community facilities) were ranked extremely low by respondents in this project (Department of Local Government 2000). 


\section{Community services and community development in local government}

The reluctance to place community services and community development high on the measurement agenda may be associated with the status of these operational areas within councils. Until the early 1970s, the primary responsibility of local government authorities was the provision of services relating to roads, rates and rubbish. In 1981 an inquiry was conducted into the role of local government in Western Australia that recommended that legislation be amended to broaden the legal mandate of local government to include community and recreation services. This was not an entirely happy process as evidenced by the first national conference on community development held in 1985, at which presenters noted a lack of coherent roles and responsibilities between federal, state and local government (LGCSAA 1999:38-41).

This confusion was partly related to problems of definition. In 1984, following the Local Government Ministers' Conference, a Task Force was formed to undertake a national review of the role of local government in community development. Their final report stated that the term community development had been applied in various ways and was often understood to be synonymous with the provision of human services. However, it should be more correctly defined as a process that was concerned with the affairs of local communities, involved community members in decision making, and encouraged community self-reliance through the mobilisation of local resources (Office of Local Government 1987:vii).

Almost two decades later, much of the same confusion relating to definitions of community services and community development remains. Individual councils are also responding differently to the challenges brought about by the implementation of National Competition Policy. Organisational culture may be an important factor both in corporate governance and in determining how councils manage relationships with their community (Hornby 2000). In essence, local government authorities may operate from either a corporate or community perspective with respective management styles reflecting either a 'top down grand plan' approach with focus on providing services to 'customers' or a community planning approach that incorporates a 'bottom up' inclusive process which relies on community empowerment and 'citizen' participation in decision making.

These issues of definition and approach assume more importance when it is realised that community activities, particularly in the areas of recreation and culture (many of which are described as community development), account for a significant portion of operating expenditure across many local government authorities in Western 
Australia (Department of Local Government 2001). It is not surprising, therefore, that local government across Australia is attempting to establish suitable indicators to measure not just efficiency, but effectiveness, of community service provision and the process of community development (City of Melbourne 2001; LGCSA 1999).

\section{Methodology}

When preparing our original research proposal, we were unaware of the quite uneven support for the whole principle of measurement of community services/development across Australia. When discussing the proposal with local government stakeholders in Western Australia, they indicated that benchmarking was not well supported, particularly within community services/development. In spite of this, there was acknowledgment of increasing demand for the development of performance indicators for community services/development, but limited understanding of how these could work.

In order to reflect these concerns, our attention was directed to the value and use of performance measures and indicators at different levels of local government, and their relevance to community workers. Several local government authorities were approached to participate in this study. Five councils, four metropolitan and one rural, agreed to be involved. While the councils are not representative of those throughout Western Australia, there is considerable diversity apparent in terms of their populations, socio-eocnomic status, and level of amenity.

The rural council ( 1 on Figure 1) services a population of less than 5000 with generally low socio-economic status, and high levels of unemployment with tourism as its major industry. The area has many retirement and recreation properties and relatively large numbers of non-resident landowners. The second council (2 on Figure 1) is located in outer suburban Perth in a semi-rural area with a population of more than 50000 of mostly low to medium socio-economic status, with a small affluent sector. This is a major regional centre with a focus on urban renewal. An inner suburban metropolitan council ( 3 on Figure 1) has a population over 20000 which enjoys high socio-economic status and a well-established level of amenity. There is a relatively large number of residents with professional backgrounds. The largest suburban metropolitan council (4 on Figure 1) has a population of more than 70000 with low to medium socio-economic status. There are a number of civic renewal projects underway, with a particular focus on the revitalisation of the commercial sector. The final inner city metropolitan council (5 on Figure 1) has a population of just under 30000 of mainly low to medium socio-economic status. The area is undergoing gentrification as professional couples and families are replacing long term residents leaving for outer suburbs. 
The research design was developed following discussion with the project's Reference Group, consisting of representatives from the Western Australian Municipal Association, the Department of Local Government, the Local Government Community Services Association of WA and a community worker from a council not actively involved in the research project.

Preliminary discussion highlighted several questions about community services/ development within local government. In order to address these, interviews were conducted with a member of the executive management team and an elected member in each council. Questions were designed to gauge levels of knowledge and awareness of community services/development issues, the importance of community services/development within council operations, and their inclusion within strategic planning and performance measurement processes.

Community workers' perspectives were elicited at two half-day workshops with staff from each of the participating councils and facilitated by one of the researchers. Community workers were presented with summaries of the interviews from managers and elected members and asked for their responses. These workers were then asked to provide written responses to all questions previously asked of elected members and executive managers.

At the second workshop on performance measurement community workers were asked what they must, should and could measure in the course of their work. Details of measurement objectives, means of measurement, and the audience for this information was also collected at this workshop. In addition, they were asked to log all performance measurement processes and procedures over a two-month period. We also asked them to identify a project current during this period, to document the project objectives as defined by themself, elected members and council management and record any performance measurement involved. Here we were interested to see what links, if any, there were between the project's objectives and performance measures undertaken.

Final presentations to community workers and to the Reference Group enabled discussion of preliminary analysis of the data collected and were useful in determining the most important issues. It is not possible to report all issues raised but issues relating to definition and importance of community services/development, vision and strategic planning, and performance measurement are discussed in the following sections. 


\section{Perspectives of community services and community development}

In order to explore participants' views of community services and community development, we asked elected members, executive managers and community workers in each of the participating councils to tell us what they understood these terms to mean; what community services their council provided and the level of importance placed on community service provision and community development by their council.

\section{Defining community services}

The term community services was defined by most informants as 'hard' (that is, visible) services, like Meals on Wheels. However, what some LGAs considered to be community services, was quite different to others. One executive manager stated that he defined community services as 'those things that we have to provide by law ... like building licenses, health permits, health inspections, that sort of thing'.

All other informants took a socio-cultural or welfare approach to community services. Library and recreation services, provision of facilities and activity programs for seniors, families, young people and children were most often stated as the types of community services provided. Services for marginalised groups such as frail aged, people with disabilities or Indigenous people were included in the community service agenda in most councils.

\section{Defining community development}

Defining community development was difficult for most informants. Responses to questions about the definition of community development were often vague, with it being described as both an outcome (such as creating a sense of identity) and a process (working with the community to develop self-responsibility). Many respondents had difficulty in articulating the difference between community development and community services and often used the terms interchangeably.

Not surprisingly, perhaps, community workers were clearer in their differentiation between community services and community development. Typical responses included defining community development as 'enhancing and also empowering the community on a broad scale' and 'coordinating, planning, advocacy and support'. 


\section{Importance of community services and community development}

All informants agreed that it was important for the community to have access to services but considerable differences existed as to how these were delivered and which were considered essential for council to provide. In some councils, community welfare was recognised as an important factor in council operations while others supported events and activities that enriched 'culture and community development' because improving the quality of community life encouraged people to live in the area.

In spite of general support for community service provision, elected members and executive managers all expressed concern regarding the increasing responsibility on LGAs because of the devolution of services from state and federal government. There was resistance to increasing levels of current service provision due to growing funding burdens and a perceived lack of autonomy in program management which is a serious issue for local government. Several executive managers stated that as the role of local government changed, there was a need for councils to 'fill the gaps' in service provision, but not to compete in the open marketplace. In contrast, community workers' most often acknowledged community services as being necessary to improve quality of life and highlighted social justice issues such as ensuring services were available to marginalised and disadvantaged groups.

Informants were also asked about the role of community workers and perhaps the most interesting response to this question came from elected members. A number of councillors stated that the role of community workers was to implement what they (councillors) and the community wanted. That is, as elected representatives in a democratic system it was their responsibility to make decisions on behalf of the community. The process by which the community made its wishes known to councillors was not transparent, however.

\section{Council focus}

Council focus appeared to be important in determining how community services/ development were incorporated into council operations. This can be conceptualised as a continuum based on management focus and style of community interaction (Figure 1) (Hornby 2000). Community workers were asked to place their council on two points - one relating to management style and the other to community interaction. These points were then joined to establish each council's position across the continuum. 


\section{Figure 1: Community workers perception of council placement on corporate-community continuum}

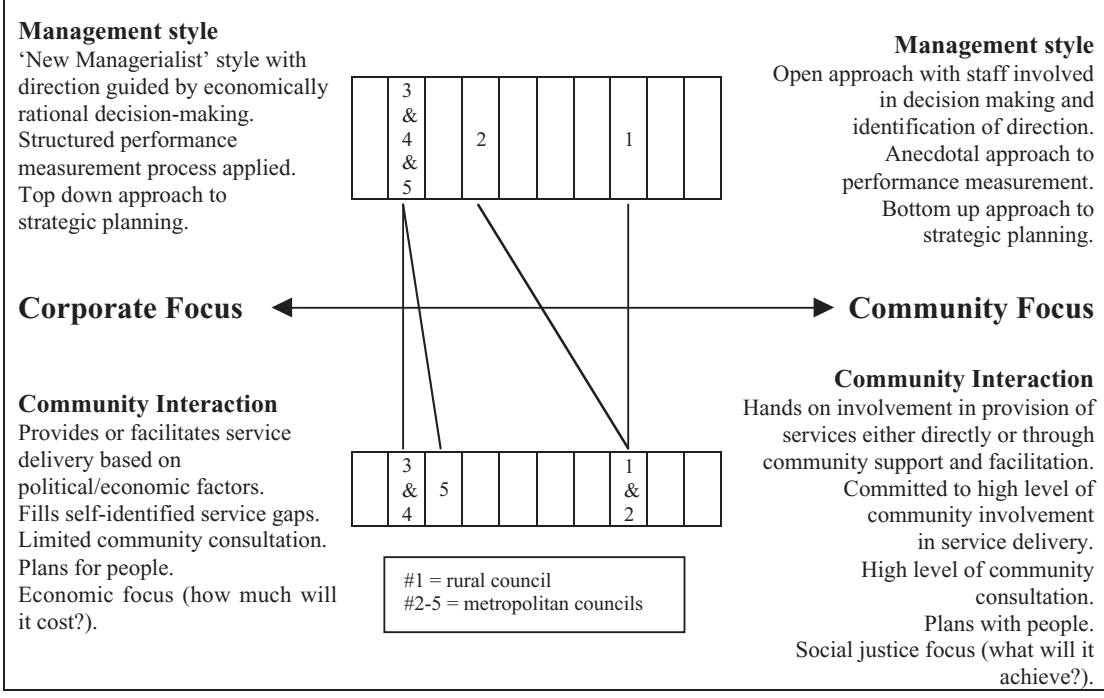

Three of the five community workers placed their councils towards the corporate end of the corporate-community continuum in both management style and community interaction (\#3,4 and 5). They stated that their councils were more likely to rely on internal judgement to make decisions about community services or community development issues without engaging in community consultation, or at best providing token opportunities for the community to be involved in decision making.

One community worker responded that while his council had historically operated under a more corporate management style, this was changing (\#2). Council's approach to community issues was becoming more orientated towards community development and community consultation in decision making. Only the community worker from the rural council stated that this council operated with an open management style and was more focused on promoting community development than simply providing community services $(\# 1)$. Whatever their position on the continuum, all of the community workers expressed the view that council focus played a major role in determining council's vision for its community and how that vision was constructed. 


\section{Vision and strategic planning}

Given the increasing prominence of strategic plans in corporatised models of governance (Hornby 2000:161), informants were invited to talk about the formulation of council vision and community development goals in their council's strategic plans. They were also asked to articulate their vision for their LGA in ten to twenty years, the role community development had in achieving this vision, and how this was incorporated into the strategic planning process.

While the community development literature stresses the need to build community visions from 'the bottom up' (Ife 1995), it was obvious that this was not how most council visions were constructed. While several elected members and executive managers spoke of community input into vision formation, managerialism seems to have intervened in that process with the view, as expressed by one elected member, that it was council's role to initiate the process and then seek agreement from the community.

Only the rural council was able to provide evidence of strong community input into the formulation of council vision. Two comprehensive community consultation projects had been conducted over the past two decades. Findings from these studies were still being used as a reference point to guide the vision of this council and its community.

The data also indicates that within each council there are differences in the way the three informant groups characterise their vision. The visions for community work and services development held by elected members (with one exception) were very general in character with references to 'pride', 'regeneration', and the 'economic sustainability' of their municipalities. These broad scale civic goals have a utopian flavour rather than a focus on specific services or processes within communities.

Some statements made by the executive managers were of a similar general tone to those of elected members, though most were more concrete. For example, managers mentioned the need to 'retain the village character' of the area, or, more negatively, to 'get rid of social problems' (code for discouraging particular disadvantaged groups to remain in the area). Economic development, urban renewal and revitalisation of commercial areas were also mentioned by several informants as an integral part of strategic planning, with the expected result of improved property values and increased 'desirability' of real estate in the local area. 
Community workers addressed both relational and material issues, with a clearer community focus. With respect to the first some spoke of the need for 'community cohesion', to 'address social issues such as reconciliation', and to 'appreciate the unique community culture'. Others wanted their councils to 'receive recognition for quality of community services', or to 'develop a leisure plan'.

These differences in the visions at different levels within the organisation are not necessarily incompatible, but they do reflect the daily concerns of the different informant groups. Perhaps the most important factor to consider here is how construction of the community's vision might influence the planning process. If fractures exist between community visions at different levels of council, and there is limited opportunity for community workers to have input to the strategic planning process, the utopian visions held by elected members may never be realised.

When informants were asked about their council's strategic plan, it seems from the replies, that few were well informed of its contents. Most executive managers and councillors were able to articulate overall objectives but were not able to describe how these objectives could or would be achieved. The data also indicates that the strategic plans were not 'live' documents as few community workers were aware of the contents of the strategic plan and in most cases, did not feel it applied to them. Strategic plans do not appear to influence the day-to-day work or the planning, monitoring or evaluation processes of community workers in the majority of the participating councils.

One community worker identified detailed community development goals within his council's strategic plan. However, he noted that they were not identified as such by all members of the management team, and he believed few people within the organisation would recognise them as concerned with community development issues. It was this community worker who had earlier identified the process of strategic plan development as consultative and inclusive. In general, however, community workers stated that they believed community development was not incorporated into councils' strategic plans except where it was equated with infrastructure development. For these community workers, the process of strategic planning was not consultative.

This finding leads to a new issue. If strategic plans incorporate performance indicators, as would be expected, but community workers have very little ownership of those plans, how can they be expected to implement and manage a meaningful and effective performance measurement process? 


\section{Performance measurement}

Given the very different beliefs and practices the literature had revealed about measurement in local government, we were interested in the extent to which participating councils were involved in performance measurement. Initially we thought asking community workers to record all performance measures they undertook would be a straightforward exercise. This was not the case. Community workers whose positions and/or programs were dependent upon external funding were much more aware of performance measurement requirements. However, the range of measurement processes described by these workers was very limited and most often related to compliance with financial accountability procedures such as meeting budget or maximising staff resources.

Three of the community workers stated that, apart from those required by external funding bodies, little or no performance measures for community services or community development were actively administered within their councils. Where present, measures related more to aspects of individual worker's performance rather than measurement of program efficiency or effectiveness.

Each community worker was asked to select a specific project and identify the objectives (from their own perspective and that of management and elected members) and related performance indicators. Only two people were able to complete the task. Most claimed that they found this exercise difficult, with one community worker admitting to being totally confused about how to approach such a task. In one case where the task was completed, linkages between objectives and measurement were well established in what was an ongoing, long-term and externally funded project. However, in the other example, there was little direct association between the project's objectives and the performance measures selected. This community worker identified the objectives of a school holiday program for young people as improving participants' self-esteem, meeting budget guidelines, and raising awareness of council involvement in assisting young people. However, the only performance measures documented related to the number of participants and determining whether the project had met financial guidelines. There was no measurement of whether the program had improved participant self-esteem or raised community awareness.

All community workers claimed there should be better monitoring of community development processes so they had more qualitative information they could use to explain and justify their work. One worker commented that management was more comfortable with the quantitative aspects of community development practice as the value-based component was hard to measure effectively. This observation was 
supported by responses to a question about the level of importance of performance measurement. While most of the elected members generally expected that performance would be measured, most found it difficult to articulate how this would happen.

While all executive managers recognised that performance measurement was something they had to do, either to facilitate management or because it was a requirement, some were quite unclear as to how this could be done with community development. Responses to this question highlight some of the differences in understanding of the measurement process. For some, performance measurement was about evaluating community satisfaction with services. Conducting regular community surveys was mentioned by several executive managers and elected members. Others implied that they should be focusing on internal performance, for example, whether projects operated to budget, but not necessarily the efficacy of their outcomes.

We also explored reasons for undertaking performance measurement. For both elected members and executive managers, accountability issues loomed largest. There were concerns raised that the implementation of NCP had led to an increase in 'jargonistic terms' such as benchmarking, market testing and key performance indicators that only confused many who worked within the community. Further, there was a fear that councils were now required to prove their effectiveness, often through a set of performance indicators imposed by other agencies.

Responses from community workers were mixed. They appeared to have limited understanding of the reasons councils chose to implement particular performance measures, or even why these types of measure might be considered important. There was little understanding of the implications of NCP guidelines or other external factors that influenced council accountability or management practice.

We were also interested in exploring how community worker effectiveness was evaluated. Elected members and executive managers were asked how they knew their community workers were doing a good job, and community workers were asked how they evaluated their own performance. Almost all executive managers mentioned a formal employee review process but this focused on individual performance as council officers, not on community worker's effectiveness or the effectiveness of programs and services they administered within the broader community. In all cases, informal community feedback and lack of complaints from the community were cited as the primary means of evaluating performance of community workers and their projects. It appears that despite all of the ensuing 
discussion regarding the importance of structured performance measurement, anecdotal evidence was the most common method of measuring effectiveness in community services and community development.

\section{Discussion}

Like other levels of the public sector, local government in Australia has been increasingly subject to pressures to demonstrate their competitiveness and improve their performance and accountability through structural reform (National Competition Council 1999). While demonstrating their greater efficiency and effectiveness, they have also assumed responsibility for a broader range of community services/ development functions, as these are progressively devolved from state and federal governments (Salvaris 2000). Benchmarking and performance measurement is part of the package taken on by local government to demonstrate their commitment to the new transparent, competitive regime.

It seems, however, that the disquiet being expressed by the Australian electorate about the impact of changes such as National Competition Policy is reflected in many local government authorities. In spite of international and national interest in measurement of community well being (Cobb \& Rixford 1998; Salvaris 2000), our evidence indicates a broad lack of understanding of and support for performance measures for community services/development. That is, there appears to be a significant gap between what the literature is telling us about measurement in local government, and what is happening on the ground, at least in Western Australia.

The message, however, is not black and white. Differences in responses between councils in this study support the notion put forward by others (Hornby 2000) that there exists a continuum of council cultures, from those with a more community focus to those characterised by corporate governance. The corporate councils are those most likely to have taken on at least the formal trappings of performance measurement, and management are more likely to be able to articulate what is supposed to happen in terms of strategic planning, objective setting and performance management. But even in these councils, the links between community development and community services objectives in the strategic plan and performance measures are not well connected. Perhaps more importantly, it is largely these councils that are least likely to employ 'bottom up' consultative processes considered essential to community development processes.

In all councils, regardless of their community/corporate orientation, responses from elected members, executive managers and community workers reflected sometimes 
quite different understandings of performance measures of community services/ development. In part, the problem relates to the imprecision of definitions of these operational areas. While community workers could articulate some significant differences between these concepts, responses from elected members and executive managers were less clear. These definitional problems make more explicable the argument that benchmarking across councils is not feasible or desirable because of the differences in operation, philosophy and practice between councils (Department of Local Government 2000).

At community worker level formal performance measurement occurs largely when demonstrating financial accountability, usually with respect to externally funded programs. Performance indicators are those items that can be easily counted - such as the number of grants awarded, or the attendance at community events. There was very little assessment of program effectiveness. In part this is because community workers are not required to demonstrate effectiveness, but it is also due to the inherently more difficult task such valid qualitative measures constitute, hence the reliance on informal and anecdotal information.

The performance measurement manual published in Western Australia (Department of Local Government 2001) makes several specific points relating to measurement. It highlights the inadequacy of measuring the number of complaints in order to evaluate service effectiveness, stating that equal validity should be given to indicators that reflect efficiency, effectiveness and comparability (either internal or external comparison) when designing performance measurement systems. Unfortunately, little assistance is offered to councils wanting to establish such indicators in strategic community development objectives, except through survey methods.

A further issue raised in this study is the apparent lack of understanding of how to match strategic objectives with suitable performance indicators. It was not unusual for performance indicators to have little bearing on stated objectives. In fact, many of the objectives identified by community workers were extremely broad and difficult to adequately measure. It was also obvious that few community workers knew how their activities were linked to their council's strategic vision or how they might link in with other areas of council operations such as infrastructure development or initiatives in community safety.

From our perspective, this research poses more questions than it has answered. We wanted to explore local government's current commitment to benchmarking and performance measurement, and how community services/development fits into such measurement. Is the gap between the published literature and research such 
as ours more apparent than real? The basic questions remain. Why is measurement important? Is it simply for accountability and to demonstrate competitiveness, or is continuous improvement also an issue? What should be measured? Should these simply be those things easily quantified, or can more valid indicators be employed? Also, how should measurement occur? Will approaches such as 'triple bottom line' accounting, currently being incorporated into strategic planning by the City of Melbourne (2001) where economic, social and environmental factors are equally considered, influence the way in which local government authorities approach performance measurement?

There are broader questions, too, about the capacities of local governments to engage in meaningful community development practice that reflects their stated goals of empowerment, participation and social justice for citizens. Currently, the evidence in Western Australia, at least, suggests that few councils have been able to move beyond the rhetorical articulation of these aspirations, particularly at management and elected member levels of engagement. As more councils take on greater responsibilities for community well being at the local level, how will they balance issues of corporate accountability with wider civic responsibility? These are the questions we are hoping future research will enable us to explore.

\section{Acknowledgments}

This research was made possible by a grant from the Institute for the Service Professions, Edith Cowan University and collaboration from the Local Government Community Services Association of Western Australia. We are grateful to members of our Reference Group for their assistance with the direction of the research and to our informants from the five participating Western Australian councils. Suggestions from two anonymous reviews were valuable.

\section{References}

Bourdieu, P. (1985) 'The forms of capital' in J.G. Richardson (Eds) Handbook of Theory and Research for the Sociology of Education, Connecticutt, Greenwood Press.

City of Melbourne (2001) Draft City Plan 2010, available online at www.melbourne.vic.gov.au/cityplan

Cobb, C. W. \& Rixford, C. (1998) 'Lessons learned from the history of social indicators', San Francisco, Redefining Progress, available online at www.rprogress.org 
Collins, J. \& Waite, T. (1998) Local Government Performance Measurement and Benchmarking Project: Stages 1 and 2, Unpublished reports for the Local Government Association of South Australia.

Commonwealth Department of Housing and Regional Development (1995) Benchmarking for Local Government, Canberra, Australian Government Publishing Service.

Cox, E. (1995) A truly civic society: Boyer Lectures 1995, Sydney, ABC Books.

Department of Local Government (2000) Consultation Report: Key Performance Indicators for Western Australian Local Government, Perth, Department of Local Government.

Department of Local Government (2001) Performance Measurement Guidelines for Western Australian Local Governments, Perth, Department of Local Government.

Hornby, F. (2000) 'Performance indicators for community and cultural development of local communities', in Proceedings of 2000 Community Development Conference (pp. 159-165), Mackay, Queensland Local Government Services Association.

Ife, J. (1995) Community Development: Creating Community Alternatives Vision, Analysis and Practice, Melbourne, Longman.

Industry Commission, (1997) Performance Measures for Councils: Improving Local Government Performance Indicators, Canberra, Commonwealth of Australia.

Kawachi, I., Kennedy, B., Lochner, K. \& Prothow-Stith, D. (1997) 'Social capital, income inequality and mortality', American Journal of Public Health, 89(8), $1187-1193$.

Leeder, S. \& Dominello, A. (1999) 'Social capital and its relevance to health and family policy', Australian and New Zealand Journal of Public Health, 23(4), 424-429. 
Local Government Community Services Association of Australia, (1999) Working Together to Develop our Communities: Good Practice and Benchmarking in Local Government Community Development and Community Services, Townsville, LGCSA.

Macneil, J., Testi, J., Cupples, J., \& Rimmer, M. (1994) Benchmarking in Australia, Melbourne, Longham.

National Competition Council, (1999) National Competition Policy: Some Impacts on Society and the Economy, Canberra, Commonwealth of Australia.

Office of Local Government (1987) Community Development, Human Services and Local Government, Report of a Task Force of the Joint Officer's Committee, Local Government Ministers' Conference.

Putnam, R. (1993) Making Democracy Work: Civic Traditions in Modern Italy, Princeton, Princeton University Press.

Salvaris, M. (2000) Community and Social Indicators: How Citizens can Measure Progress, Report prepared for the Institute of Social Research, Melbourne, Swinburne University of Technology.

Victoria University of Technology (1997) Public Sector Management, Melbourne, Victoria University of Technology, Public Sector Unit, Faculty of Business. 
